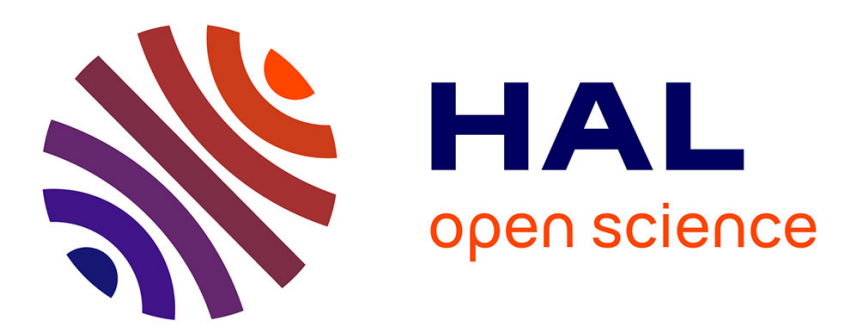

\title{
Numerical Modeling of Glucose biosensor with pH-based Electrochemical Field Effect Transistor Device
}

Moussa Ba, Abdou Karim Diallo, El Hadji Babacar Ly, Jérôme Launay, Pierre Temple-Boyer

\section{- To cite this version:}

Moussa Ba, Abdou Karim Diallo, El Hadji Babacar Ly, Jérôme Launay, Pierre Temple-Boyer. Numerical Modeling of Glucose biosensor with pH-based Electrochemical Field Effect Transistor Device. IEEE Transactions on Electron Devices, 2020, 67 (4), pp.1787-1792. 10.1109/TED.2020.2975739 . hal-02881764

\author{
HAL Id: hal-02881764 \\ https://hal.laas.fr/hal-02881764
}

Submitted on 26 Jun 2020

HAL is a multi-disciplinary open access archive for the deposit and dissemination of scientific research documents, whether they are published or not. The documents may come from teaching and research institutions in France or abroad, or from public or private research centers.
L'archive ouverte pluridisciplinaire HAL, est destinée au dépôt et à la diffusion de documents scientifiques de niveau recherche, publiés ou non, émanant des établissements d'enseignement et de recherche français ou étrangers, des laboratoires publics ou privés. 


\title{
Numerical Modeling of Glucose biosensor with pH-based Electrochemical Field Effect Transistor Device
}

\author{
Moussa Ba, Abdou Karim Diallo*, El Hadji Babacar Ly, Jérôme Launay, Pierre Temple-Boyer
}

\begin{abstract}
In this work, we present a new model for glucose detection using an Electrochemical Field Effect Transistor (ElecFET) with a MATLAB ${ }^{T M}$ software. ElecFET is a device in which the basic element is a pH-ChemFET $(\mathrm{pH}-$ sensitive Chemical Field Effect Transistor) designed with an integrated platinum microelectrode around the sensitive gate dielectric capable to trigger electrochemical reactions. A number of parameters such as polarization time $\left(T_{\text {pol }}\right)$ and polarization voltage $\left(V_{p}\right)$ have been investigated, as well as the enzymatic unit number per volume $\left(\mathrm{N}_{\mathrm{enz}}\right)$, the Michaelis constant $\left(\mathrm{K}_{\mathrm{M}}\right)$ and the glucose concentration $\left(\mathrm{C}_{0}\right)$. Each of the aforementioned parameters influences the glucose sensor response. Experimental data compared with our numerical model showed a reasonable fit.
\end{abstract}

Index Terms-Modeling, ChemFET, Microelectrode, ElecFET, Glucose sensor, Biosensor

\section{INTRODUCTION}

$\mathbf{N}$ OWADAYS, it is no longer necessary to demonstrate the prominence to detect or monitor the glucose concentration either in the blood or in a daily diet. The detection of glucose can be found in various fields such as, environment, food industry, fuel cells [1], to name a few. However, one of the flagship applications is in clinical field. Detecting or monitoring the level of glucose in the blood is an excellent indicator of diabetes. This chronic and non-communicable disease (NCD) is one of the most important public health challenges in this 21 st century.The World Health Organization has registered 450 million cases of diabetes worldwide and this number could reach 700 million in 2045 [2].

From that point of view, several types of biosensors dedicated to glucose detection have been studied. Most of the techniques used for glucose detection are based on optical or electrochemical detections [3, 4]. However, the optical methods are expensive and not easy to use for specific applications. Therefore, the most studied glucose detection devices use electrochemistry and particularly the amperometry technique, while potentiometry is still less explored. Both methods, i.e., amperometry and potentiometry, work in liquid phase.

Manuscript received December 30, 2019. This work was supported by CEA-MITIC, Gaston Berger University.

M. Ba, A. K. Diallo, E. H. B. Ly are with the Département de Physique Appliquée, Université Gaston Berger de Saint-Louis, Sénégal, ("${ }^{*}$ corresponding author: abdou-karim.diallo@ugb.edu.sn).

J. Launay, P. Temple-Boyer are with LAAS-CNRS, 7 avenue du colone Roche, F-31400 Toulouse, France and Université de Toulouse, UPS LAAS, F-31400 Toulouse, France.
Amperometry uses the oxido-reduction properties leading to the development of electrodes and electrochemical cells [5, 6], while potentiometry focuses on the working principle of ion sensitive electrode (ISE) and ChemFET resulting to charge trapping at the solid/liquid interface [7, 8] followed by potential changes. The combination of both techniques is very promising and has been initiated earlier by Sohn et al. [9] and later by Diallo et al. [10]. The device resulting from the combination of the aforementioned techniques has been named ElecFET and comprises a pH-ChemFET associated to an integrated platinum microelectrode around the sensitive gate area. The platinum microelectrode is used to trigger the electrochemical reactions while the $\mathrm{pH}$-ChemFET measures the $\mathrm{pH}$ variations around the gate dielectric. ElecFET has been used for the detection of dissolved oxygen [9], hydrogen peroxide $\left(\mathrm{H}_{2} \mathrm{O}_{2}\right)$, lactate and glucose [10-12], opening a promising way for biomolecules produced by reactions related to oxidase-based enzymes. Despite efforts made for understanding the ElecFET working principle, very few models have been studied to predict the sensor response with this device,compared to what is observed in BioFET (Biologically sensitive FET)[13,14] and especially in EnFET (Enzymatic FET)[15-20]. The only models for ElecFET are those proposed by Diallo et al. [21] and Aoun et al.[22] using respectively MATLAB and COMSOL Multiphysics 2D for the detection of hydrogen peroxide and water electrolysis. In this study, we present a model and experimental results of glucose biosensor based on ElecFET device using MATLAB software. We first considered the transformation of glucose into hydrogen peroxide $\mathrm{H}_{2} \mathrm{O}_{2}$ thanks to the glucose oxidase. Then, $\mathrm{H}_{2} \mathrm{O}_{2}$ is electrochemically transformed into hydronium ions $\mathrm{H}_{3} \mathrm{O}^{+}$ through the platinum microelectrode. Finally, the $\mathrm{H}_{3} \mathrm{O}^{+}$ions diffuse into the solution leading to local $\mathrm{pH}$ changes detected by the $\mathrm{pH}-\mathrm{ChemFET}$. Beyond diffusion phenomena of glucose and all the chemical species, the main influential parameters such as enzymatic unit number per volume $\left(N_{\text {enz }}\right)$, Michaelis constant $\left(K_{M}\right)$ as well as the polarization $\left(V_{p}\right)$ voltage and polarization time $\left(T_{p o l}\right)$ on the microelectrode, are studied. Experimental data have been correlated to the theory in order to assess the glucose biosensor response.

\section{EXPERIMENTAL SECTION AND MODELING}

\section{A. Experimental Section}

The realized ElecFET and the enzymatic functionalization have been studied in previous works [10]. Fig. 1a is a 


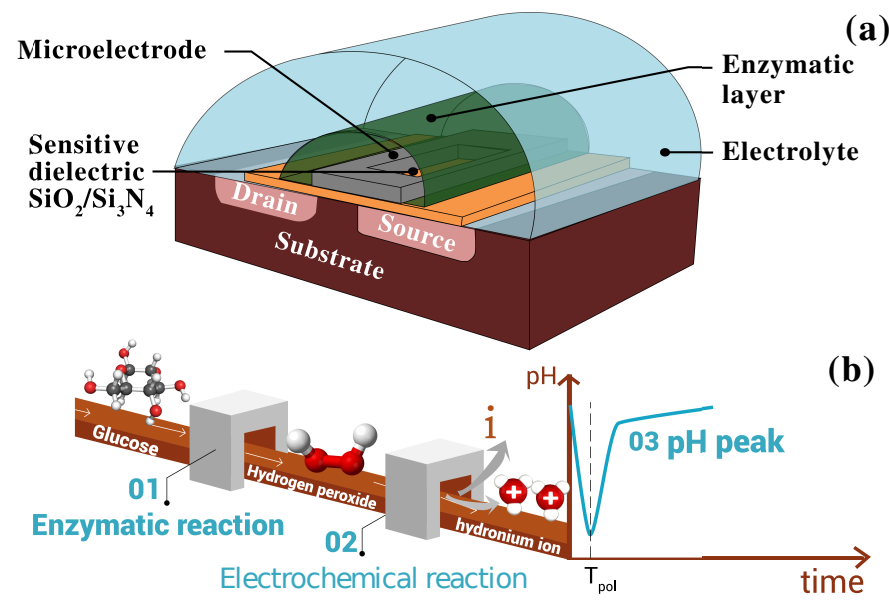

Fig. 1. (a) Schematic representation, (b) glucose detection principle using ElecFET device.

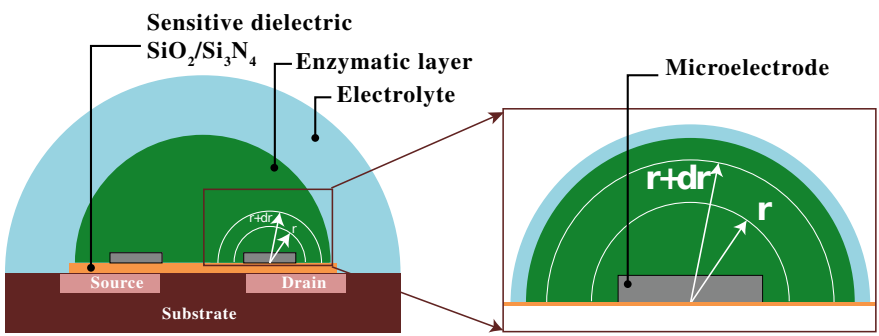

Fig. 2. Description of one-dimensional model in radial coordinate.

schematic representation and Fig. 1b illustrates the glucose detection principle using ElecFET.

\section{B. Modeling}

The different reactions during ElecFET operation are briefly described in Fig. 1b. We first considered the enzymatic reaction of glucose into hydrogen peroxide and the diffusion of different biochemical species(step 1). Secondly, by polarizing the platinum microelectrode, electrochemical reaction is triggered and $\mathrm{H}_{2} \mathrm{O}_{2}$ transformed into hydronium ions $\mathrm{H}_{3} \mathrm{O}^{+}$(step $2)$. The current produced during this electrochemical reaction depends on the $V_{p}$ and $T_{p o l}$. Finally, the hydronium ions released from this reaction created a local $\mathrm{pH}$ change detected by the traditional $\mathrm{pH}-\mathrm{ChemFET}$ (step 3 ).

Fig. 2 represents the Cross-section of the ElecFET device describing the one-dimensional model in radial coordinate. To simplify the schema of the description of one-dimensional model in radial coordinate, we only consider one part of the microelectrode in the cross section of fig. 2.

- Modeling of glucose oxidase enzymatic reaction The glucose oxidase (GOD) catalyzes the glucose oxidation according to the following reaction(Reaction 1 ):

glucose $+\mathrm{O}_{2} \stackrel{\text { glucose oxidase }+\mathrm{H}_{2} \mathrm{O}}{\longrightarrow}$ gluconic acid $+\mathrm{H}_{2} \mathrm{O}_{2}$ (Reaction 1)

The term of production/consumption $\left(g_{\text {enz }}\right)$ corresponding to the production of hydrogen peroxide from the glucose substrate is expressed in moles per unit of volume and unit of time and written as:

$$
g_{e n z}=a_{M} * N_{e n z} \frac{[S]}{[S]+K_{M}} .
$$

Where $a_{M}$ is the maximal enzyme activity, $N_{e n z}$ is the enzymatic unit number per volume, $[S]$ is the glucose concentration in solution and $K_{M}$ is the glucose oxidase Michaelis constant. The term $g_{\text {enz }}$ exists only within the enzymatic layer, otherwise it is equal to zero. In the model, this layer thickness is set to $1 \mu \mathrm{m}$, based on estimates of the enzyme deposition rate.

\section{- Modeling of the electrochemical production of $\mathrm{H}_{3} \mathrm{O}^{+}$}

By applying to the integrated microelectrode a voltage at least greater than the equilibrium potential for $\mathrm{H}_{2} \mathrm{O}_{2}$ oxidation, the hydrogen peroxide resulting from the enzymatic reaction is oxidized and $\mathrm{H}_{3} \mathrm{O}^{+}$ions are released according to the reaction:

$$
\mathrm{H}_{2} \mathrm{O}_{2}+2 \mathrm{H}_{2} \mathrm{O} \rightarrow \mathrm{O}_{2}+2 \mathrm{H}_{3} \mathrm{O}^{+}+2 \mathrm{e}^{-} \text {(Reaction 2) }
$$

The concentration of the $\mathrm{H}_{3} \mathrm{O}^{+}$ions resulting from this reaction is given by the following relation:

$$
\left(\frac{\partial\left[H_{3} O^{+}\right](r, t)}{\partial t}\right)=2 g_{\text {elec }}=2\left[H_{2} O_{2}\right](r, t) \frac{K_{1+}}{d r} \exp \left(\frac{F\left(\Delta V_{p}\right)}{R T}\right) .
$$

Where $g_{\text {elec }}$ represents the production/consumption rate according to the associated electrochemical reaction, $\Delta V_{p}=\left(V_{p}-E_{1+}\right)$ with $E_{1+}$ the equilibrium potential for $\mathrm{H}_{2} \mathrm{O}_{2}$ oxidation, $K_{1+}=5.10^{-8} \mathrm{~m} / \mathrm{s}$ is the standard rate constant for the $\mathrm{H}_{2} \mathrm{O}_{2}$ oxidation, $\mathrm{F}$ is the Faraday constant $(F=96.485 \mathrm{C} / \mathrm{mol}), \mathrm{R}$ is the ideal gas constant $(R=8.32 \mathrm{~J} /(\mathrm{K} \bullet \mathrm{mol})), T=300 \mathrm{~K}$ is the absolute temperature.

\section{- Influence of water self-ionization}

According to water self-ionization :

$$
\left.2 \mathrm{H}_{2} \mathrm{O} \leftrightarrow \mathrm{H}_{3} \mathrm{O}^{+}+\mathrm{OH}^{-} \text {(Reaction } 3\right)
$$

The variation of $\mathrm{H}_{3} \mathrm{O}^{+}$ions concentration is equal to those $O H^{-}$ions. It is noted $\phi$ and its expression is given by :

$$
\begin{gathered}
\phi=\Delta\left[\mathrm{H}_{3} \mathrm{O}^{+}\right]=\Delta\left[\mathrm{OH}^{-}\right] . \\
\phi=\frac{\sqrt{\left(\left[\mathrm{H}_{3} \mathrm{O}^{+}\right]-\left[O \mathrm{H}^{-}\right]\right)^{2}+4 K_{w}}-\left[\mathrm{H}_{3} \mathrm{O}^{+}\right]-\left[O H^{-}\right]}{2} .
\end{gathered}
$$

Where $K_{w}$ is the ionic product of water.

\section{- Modeling of diffusion phenomena}

The diffusion model is based on the Fick's diffusion equation, assuming a one-dimensional model in spherical coordinates with the radial component $r$ (Fig. 2) :

$$
\frac{\partial C(r, t)}{\partial t}=D \frac{1}{r^{2}} \frac{\partial}{\partial r}\left(r^{2} \frac{\partial C(r, t)}{\partial r}\right)+\epsilon_{1} g_{\text {enz }}(r, t)+\epsilon_{2} g_{\text {elec }}(r, t) .
$$

Where $C(r, t)$ describes the concentration of the species, $D$ the associated diffusion coefficient, $\epsilon_{i}= \pm 1$ (with $i=1$ or 2 ), for a production $\epsilon_{i}=+1$ while for a consumption $\epsilon_{i}=$ $-1, g_{\text {enz }}$ represents the production/consumption according to the associated enzymatic reaction. The term of $g_{\text {elec }}$ is obtained only when a polarization voltage is applied on the microelectrode during $T_{p o l}$. As a result, the diffusion equations are:

$$
\frac{\partial[\text { glucose }](r, t)}{\partial t}=D_{\text {glucose }} \frac{1}{r^{2}} \frac{\partial}{\partial r}\left(r^{2} \frac{\partial[\text { glucose }](r, t)}{\partial r}\right)-g_{\text {enz }}(r, t) .
$$




$$
\begin{gathered}
\frac{\partial\left[\mathrm{H}_{2} \mathrm{O}_{2}\right](r, t)}{\partial t}=D_{\mathrm{H}_{2} \mathrm{O}_{2}} \frac{1}{r^{2}} \frac{\partial}{\partial r}\left(r^{2} \frac{\partial\left[\mathrm{H}_{2} \mathrm{O}_{2}\right](r, t)}{\partial r}\right)+g_{\text {enz }}(r, t)-g_{\text {elec }}(r, t) \\
\frac{\partial\left[\mathrm{H}_{3} \mathrm{O}^{+}\right](r, t)}{\partial t}=D_{\mathrm{H}_{3} \mathrm{O}^{+}} \frac{1}{r^{2}} \frac{\partial}{\partial r}\left(r^{2} \frac{\partial\left[\mathrm{H}_{3} \mathrm{O}^{+}\right](r, t)}{\partial r}\right)+2 g_{\text {elec }}(r, t)
\end{gathered}
$$

All the diffusion constants have been calculated according to the Einstein's Equation [15; 16]:

$$
D=A \frac{k T}{\sqrt[3]{M}} .
$$

Where $A$ is a parameter related to the electrolyte, $k$ the Boltzmann's constant, $T$ the absolute temperature and $M$ is the molar mass of the associated molecule.

The initial condition related to mass transport of $\mathrm{H}_{3} \mathrm{O}^{+}$ions is given by:

$$
\left[H_{3} \mathrm{O}^{+}\right](r, 0)=10^{-p H_{0}} \Leftrightarrow\left[O H^{-}\right](r, 0)=K_{w} 10^{p H_{0}} .
$$

At the upper interface of the electrolyte $\left(r=r_{\max }\right)$ and the lower interface $(r=0)$, the interface is assumed to be impermeable(i.e, there is no diffusion at the upper limits and lower):

$$
\left(\frac{\partial C(r, t)}{\partial r}\right)_{r=0}=\left(\frac{\partial C(r, t)}{\partial r}\right)_{r=r_{\max }}=0 .
$$

\section{- Modeling of the $\mathrm{pH}$-ChemFET response}

The $\mathrm{pH}$-ChemFET threshold voltage $V_{T}$ variation also considered as the sensor response was estimated according to the following equation:

$$
\delta V_{T}=S_{0}\left(p H(d, t)-p H_{0}\right) .
$$

where $S_{0}$ is the $\mathrm{pH}$-ChemFET sensitivity according to the sitebinding model and $d$ is the distance between the integrated microelectrode and the $\mathrm{pH}-\mathrm{ChemFET}$ gate sensitive area.

\section{Results AND Discussions}

In previous work, several attempts have been done to demonstrate glucose sensor that used conventional EnFET [2326], but the major drawbacks of its rapid progress in practical applications is the limitation of the dynamic range of the biosensor response because of the insufficient concentration of dissolved oxygen and the low dissociation constant of gluconic acid $[12 ; 26]$. The advantages obtained with this ElecFET results from the platinum microelectrode added to the device. Indeed, this microelectrode is firstly responsible to the $\mathrm{H}_{2} \mathrm{O}_{2}$ electrolysis producing oxygen which is recycled in glucose oxidation reaction and establishing an extended dynamic range. Secondly, the oxidation reaction of hydrogen peroxide at the platinum microelectrode is fast, maintained over time as wished and produces two hydronium ions compared to gluconic acid dissociation used solely in EnFET. This second point enables to control the electrochemical reaction and therefore the sensor response. The ElecFET model is simulated by MATLAB tool and the parameters and values used for the modeling are summarized in table I.

- Production/consumption of chemical species from enzymatic reaction: diffusion phenomena
TABLE I

PARAMETERS AND VALUES USED IN THIS MODELING

\begin{tabular}{|l|l|l|}
\hline Parameter & Signification & Value \\
\hline$T_{p o l}$ & Polarization time & $10 \mathrm{~s}$ \\
$V_{p}$ & Polarization voltage & $1 \mathrm{~V}$ \\
$E_{1}+$ & Equilibrium potential for & $0.7 \mathrm{~V}$ \\
& $\mathrm{H}_{2} \mathrm{O}_{2}$ oxidation & \\
$S_{0}$ & Sensitivity & $59 \mathrm{mV} / \mathrm{pH}$ \\
$p \mathrm{H}_{0}$ & Initial pH of the solution & 7 \\
$\mathrm{C}_{0}$ & Initial concentration of glucose & $5.10^{-2} \mathrm{~mol} / \mathrm{L}$ \\
{$\left[\mathrm{H}_{2} \mathrm{O}_{2}\right]_{0}$} & Initial concentration of $\mathrm{H}_{2} \mathrm{O}_{2}$ & $0 \mathrm{~mol} / \mathrm{L}$ \\
$N_{e n z}$ & Enzymatic unit number per & $10^{4}$ units $/ \mathrm{cm}^{3}$ \\
$K_{M}$ & volume & \\
& Michealis Constant of glucose & $7.15 .10^{-2} \mathrm{~mol} / \mathrm{L}$ \\
\hline
\end{tabular}
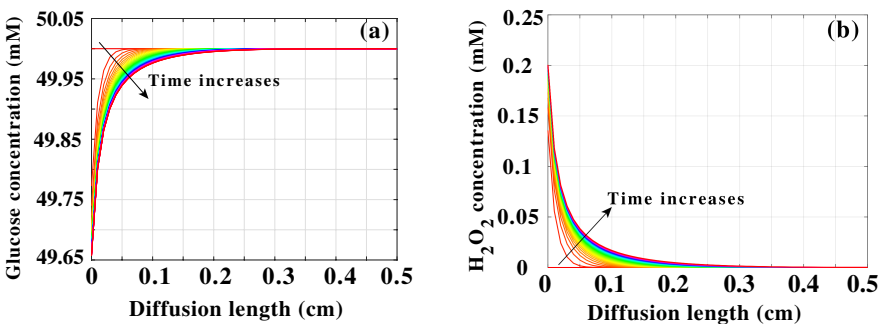

Fig. 3. (a) Glucose concentration and (b) hydrogen peroxide concentration versus diffusion length at different times and keeping constant all the parameters.

Fig. $3 \mathrm{a}$ and $3 \mathrm{~b}$ show respectively the glucose and hydrogen peroxide concentration changes in the enzymatic layer as a function of the diffusion length over time. As we can see in Fig. 3a, close to the sensitive gate, the glucose concentration decreases as the time increases, while beyond this area, i.e., deep into the bulk solution, it remains constant. Opposite behavior is observed with respect to hydrogen peroxide. The concentration of $\mathrm{H}_{2} \mathrm{O}_{2}$ increases close to the sensitive zone while further in the solution it decreases. These behaviors are explained by the presence of glucose oxidase enzyme which catalyzes the reaction of glucose in the presence of oxygen to hydrogen peroxide. The local production of this $\mathrm{H}_{2} \mathrm{O}_{2}$ leads to its increase, a consequence of the glucose consumption (concentration decreasing) in the enzymatic layer. The longer the time increases, the more diffusion occurs. It should be noted that beyond the enzymatic layer, the concentration of hydrogen peroxide is very low (or even zero) as shown in Fig. 3b. At the same time, the more the time increases the more diffused glucose into the enzyme layer, thereby leading to its oxidation. Consequently, the glucose concentration decreases near the detection area of the sensor device. This confirms the consumption/production of glucose/ $\mathrm{H}_{2} \mathrm{O}_{2}$ respectively through the enzymatic reaction.

\section{- Electrochemical reaction and $p H$ detection}

The detection of $\mathrm{pH}$ by the $\mathrm{pH}-\mathrm{ChemFET}$ is performed when $\mathrm{H}_{3} \mathrm{O}^{+}$ions are produced. The reaction of glucose using their specific glucose oxidase enzyme (Reaction 1) generates $\mathrm{H}_{2} \mathrm{O}_{2}$ molecules. As mentioned in the previous section, $\mathrm{H}_{2} \mathrm{O}_{2}$ is converted on the platinum electrode giving oxygen and two $\mathrm{H}_{3} \mathrm{O}^{+}$ions (Reaction 2) diffusing into the enzymatic layer and beyond. Fig. 4 illustrates the $\mathrm{H}_{3} \mathrm{O}^{+}$concentration changes versus diffusion length. As can be seen, far from the 


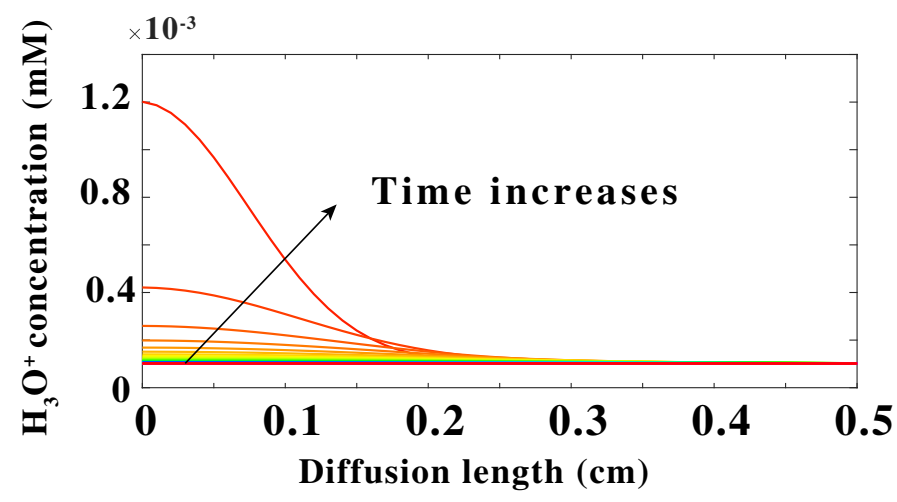

Fig. 4. Hydronium ions concentration versus diffusion length at different times by keeping constant all the parameters.
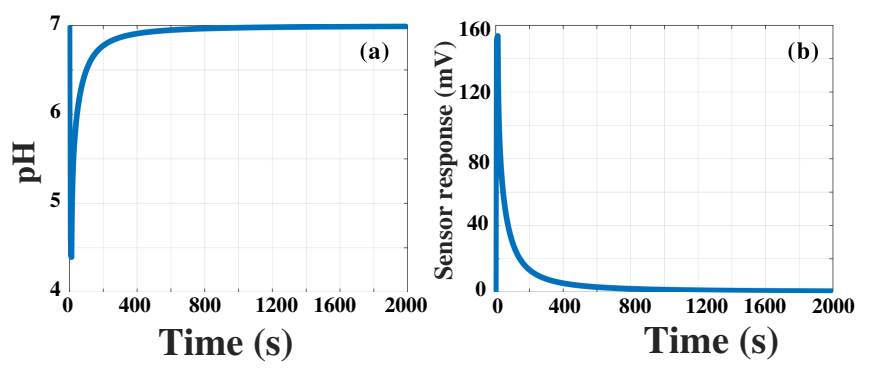

Fig. 5. (a) $\mathrm{pH}$ variation and (b)sensor response variation versus time by keeping constant all the parameters.

detection area, i.e., deep into the bulk solution, the $\mathrm{H}_{3} \mathrm{O}^{+}$ concentration is equal to its initial value $\left(10^{-7} M\right)$, whereas close to the $\mathrm{Si}_{3} \mathrm{~N}_{4}$ /solution interface the concentration is higher. Similar principle related to diffusion phenomena mentioned above could explain this change in concentration. When the electrochemical reaction is triggered gradually as time increases, as long as this reaction occurs, the local production of $\mathrm{H}_{3} \mathrm{O}^{+}$is maintained and the diffusion phenomena keep going. Therefore, on the platinum microelectrode covered by the enzymatic layer, the concentration of hydronium ions are more and more important and further in the solution it is very low.

By applying a polarization $V_{p}=1 \mathrm{~V}$ on the microelectrode for a during $T_{p o l}=10 \mathrm{~s}$ (by keeping $C_{0}, N_{e n z}, K_{M}$, and all the parameters constant), the generation of $\mathrm{H}_{3} \mathrm{O}^{+}$ions is triggered. By removing the polarization after $T_{\text {pol }}$, we observe diffusion phenomena with a return to the initial state as observed in fig. 5a. The local $\mathrm{pH}$ variations are recorded by the $\mathrm{pH}$-ChemFET and result in a potential change as can be seen in Fig. 5b. The sensor response related to the potential variations, changes from $0 \mathrm{~V}$ to $158 \mathrm{mV}$ corresponding respectively to $\mathrm{pH}=7$ and $\mathrm{pH}=4$. This demonstrates that localized impulsional $\mathrm{pH}$ variations can be effectively obtained near the integrated microelectrode and detected at the adjacent $\mathrm{pH}$-sensitive surface after glucose oxidation by the glucose oxidase enzyme.

\section{- Influence of main parameters for glucose detection}

In this section the main potential parameters influencing the sensor response have been investigated. Such parameters are the glucose concentration, polarization voltage, polarization

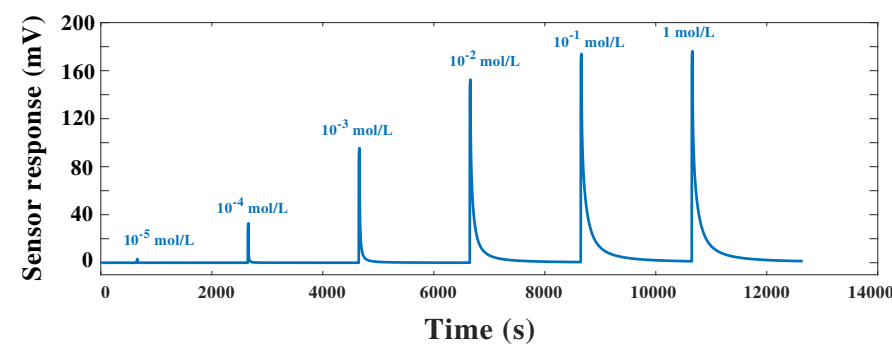

Fig. 6. Sensor response variation over time by successively changing the glucose concentration.

time, enzymatic unit number per volume and the Michaelis constant.

Fig. 6 represents the sensor response over time with different glucose concentrations in the range of $\left[10^{-5} \mathrm{~mol} / \mathrm{L}\right.$ $1 \mathrm{~mol} / \mathrm{L}]$. As observed, the sensor response increases with glucose concentration. It linearly increases from $C_{0}=10^{-4}$ $\mathrm{mol} / \mathrm{L}$ to $C_{0}=10^{-1} \mathrm{~mol} / \mathrm{L}$ with potential changes of 20 $\mathrm{mV}$ and $175 \mathrm{mV}$ respectively, giving thus a linear detection range. Beyond $C_{0}=10^{-1} \mathrm{~mol} / \mathrm{L}$, we observe a saturation effect that could be the consequence of glucose diffusion phenomena from the solution towards the enzymatic layer. Fig. $7 \mathrm{a}$ shows the sensor response versus glucose concentration in logarithmic scale for different polarization voltages. By keeping $V_{p}$ constant, the sensor response linearly increases before saturating. This saturation behavior starts from $10^{-1}$ $\mathrm{mol} / \mathrm{L}$ of glucose regardless of the polarization voltage. From Fig. 7a, we can note that: (i) irst, it is found that the sensor sensitivity decreases for low $V_{p}$, and in the same way, the greater the polarization on the platinum microelectrode, the higher the sensitivity. The sensitivity changes from $8 \mathrm{mV} / \mathrm{dec}$ to $46 \mathrm{mV} / \mathrm{dec}$ for respectively $0.8 \mathrm{~V}$ and $0.95 \mathrm{~V}$ of $V_{p}$. (ii) Then the limit of detection is affected by $V_{p}$. As can be seen for $V p=0.85 \mathrm{~V} ; 0.90 \mathrm{~V}$ and $0.95 \mathrm{~V}$, the glucose detection limits are respectively $10^{-3} \mathrm{~mol} / \mathrm{L}, 10^{-4} \mathrm{~mol} / \mathrm{L}$ and $10^{-5} \mathrm{~mol} / \mathrm{L}$. (iii) Finally, the sensor response increases as the polarization increases. This behavior is shown by the figure in insert which represents the sensor response versus $V_{p}$. There is clearly an exponential dependence of the sensor response polarization as evidenced by the Butler-Volmer theory.

An increase of polarization time has a very slight influence on the sensitivity. In addition, the limit of detection remains almost unchanged. The only notable variation recorded is the sensor response increase as $T_{p o l}$ increases. For $T_{p o l}=0.5$ $\mathrm{s}$ and $250 \mathrm{~s}$, the potential variations are respectively 160 $\mathrm{mV}$ and $180 \mathrm{mV}$ as illustrated in Fig. 7b. The insert of Fig. $7 b$ represents the sensor response versus polarization time. We note an increase of the sensor response followed by saturation. Polarization on the microelectrode with $V_{p}$ during $T_{p o l}$ maintains the electrochemical reaction of hydrogen peroxide as long as such a polarization keeps going. This enables to keep producing $\mathrm{H}_{3} \mathrm{O}^{+}$ions until the phenomena related to chemical species diffusion induce saturation effects on the sensor response. The enzymatic unit number per volume is one of the most important parameters and depends on the enzyme preparation. So, we can also act on this parameter to control the sensor response. Fig. 8a shows the influence 

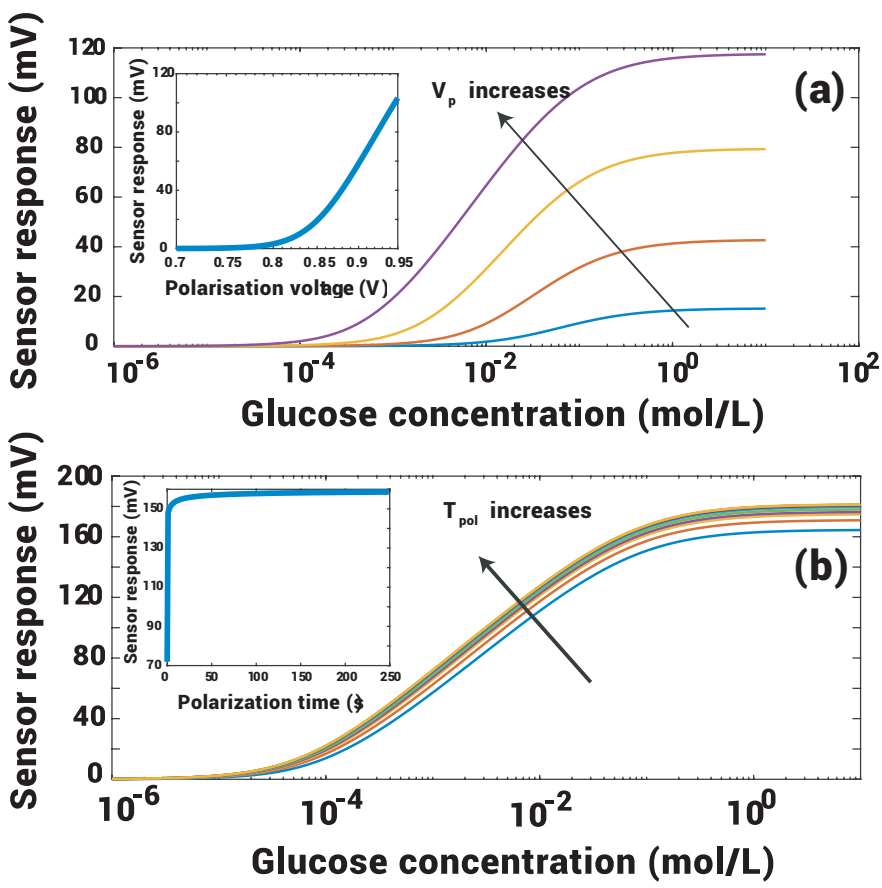

Fig. 7. (a) Sensor response versus glucose concentration in logarithmic scale with different $\boldsymbol{V}_{\boldsymbol{p}}=0.85 \mathrm{~V} ; 0.90 \mathrm{~V}$ and $0.95 \mathrm{~V}$ (insert we show sensor response versus $V_{p}$ ).(b) Sensor response versus glucose concentration in logarithmic scale with different $\boldsymbol{T}_{\boldsymbol{p o l}}=0.5 \mathrm{~s} ; 2 \mathrm{~s} ; 5 \mathrm{~s} ; 10 \mathrm{~s} ; 20$ s; 50 s; 100 s; 180 s; $200 \mathrm{~s}$ and $250 \mathrm{~s}$ (insert represents sensor response versus $\left.\boldsymbol{T}_{p o l}\right)$.

of $N_{e n z}$ on the sensor response. It is found that this $N_{e n z}$ directly affects the biosensor sensitivity, it decreases when the enzymatic layer is weakly concentrated in glucose oxidase. For $N_{\text {enz }} \geq 10^{3}$ units $/ \mathrm{cm}^{3}$, there is no sensitivity increase. It is important to mention that the enzymatic unit number is involved in the generation/consumption of species as described by equation (2), so the higher the $N_{e n z}$ is, the greater the enzymatic kinetics increases, leading to a sensitivity increase. This increase of $N_{e n z}$ promotes the glucose consumption and therefore $\mathrm{H}_{2} \mathrm{O}_{2}$ creation $\left(\mathrm{H}_{3} \mathrm{O}^{+}\right.$creation). We can also record an increase of sensor response as well as a decrease of the limit of detection when $N_{e n z}$ increases. Fig. 8b shows the sensor response versus glucose concentration in logarithmic scale with different Michaelis constant $K_{M}$. The Michaelis constant is specific to the enzyme and reflects its affinity with substrate, the larger it is, and the more the substrate is fixed poorly on the enzyme. It assesses the reaction kinetics and the lower the value, the faster the reaction. From Fig. 8b, neither the sensitivity nor the sensor response is affected. However, we can observe a shift of glucose detection limit. When $K_{M}$ increases the glucose detection limit shifts towards high concentrations. The Michaelis constant help then to determine the concentration ranges related to linear operation of ElecFETbased biosensor, but has no influence on the sensitivity.

\section{- Comparison between theory and experimental data}

In this section we compare the experimental data with our model. In order to validate our model different sensor responses have been recorded using the following parameters: $S_{0}=50 \mathrm{mV} / \mathrm{pH}, N_{\text {enz }}=150$ units $/ \mathrm{cm}^{3}, K_{M}=$
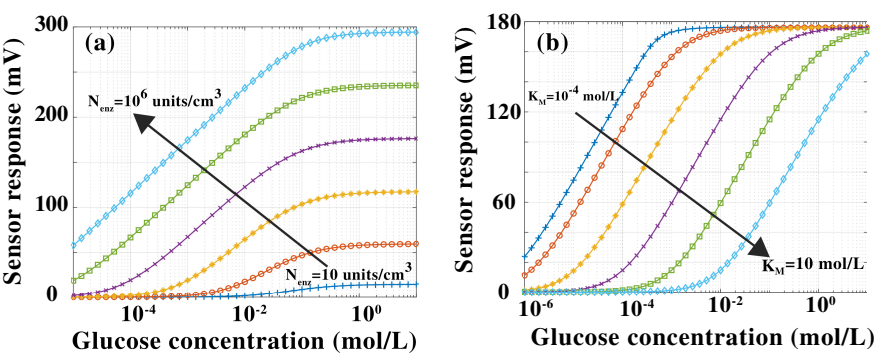

Fig. 8. Sensor response versus glucose concentration in logarithmic scale with (a) different $\boldsymbol{N}_{e n z}$ and (b) different $\boldsymbol{K}_{M}$.

$10^{-2} \mathrm{~mol} / \mathrm{L}, p H=7, \Delta V_{p}=0.27 \mathrm{~V}$.

Fig. $9 \mathrm{a}$ and $9 \mathrm{~b}$ show comparative studies between theory/experiment, and a good similarity is noted. For both fig. $9 \mathrm{a}$ and $9 \mathrm{~b}$, we can see that the sensor response curve in experimental studies shows a similar shape compared with theoretical curve. Our numerical model shows that the sensor response linearly increases with glucose concentration in solution and saturates for the highest values (Fig. 9a). This saturation phenomenon is related to the ElecFET detection principles as previously mentioned. Indeed, in the presence of glucose, $\mathrm{H}_{2} \mathrm{O}_{2}$ is created thanks to the glucose oxidase enzyme. By applying a positive voltage on the platinum microelectrode in order to trigger the electrochemical reaction, $\mathrm{H}_{2} \mathrm{O}_{2}$ is transformed with $\mathrm{H}_{3} \mathrm{O}^{+}$ions generation and therefore a local $\mathrm{pH}$ decrease. As the glucose concentration increases, the $\mathrm{H}_{3} \mathrm{O}^{+}$ions production also increases. Nevertheless, the $\mathrm{H}_{3} \mathrm{O}^{+}$ion increase is limited by diffusion and electromigration phenomena, leading to a new chemical equilibrium at the microscale. Fig. 9b shows the reproducibility measurement for $T_{p o l}=15 \mathrm{~min}$. A reasonable fit between the model and the experimental data is recorded. It may be noted that the sensor responses in the theoretical case for both fig. 9a and $9 \mathrm{~b}$ show slightly higher variations than in the experimental case. Additionally, the experimental curve in Fig. 9b shows a return to equilibrium slower than that obtained by theory. The discrepancy recorded between simulation and experimental data is probably due to a possible drop of glucose oxidase activation, processing or storage conditions and the effect of buffer properties. Buffer solution is of great importance in biosensor applications. Several works reported on the buffer properties which enhance the response and the stability of the biosensor $[22,27,28]$. In our model the chemical effect of the buffer solution was not considered (and therefore neglected) in order to better understand the ElecFET detection/transduction principles. Despite all these considerations, an acceptable fit has been obtained with experimental results.

\section{CONCLUSION}

In this paper we have studied a new model using ElecFET device for glucose detection. The main influential parameters have been investigated. The Michaelis constant helps to determine concentration ranges related to linear operation of the ElecFET-based biosensor, but has a no significant influence on the sensitivity. In the meanwhile, enzymatic unit number increases the sensitivity and the detection range. The polarization time has no effect on the sensitivity and the dynamic 

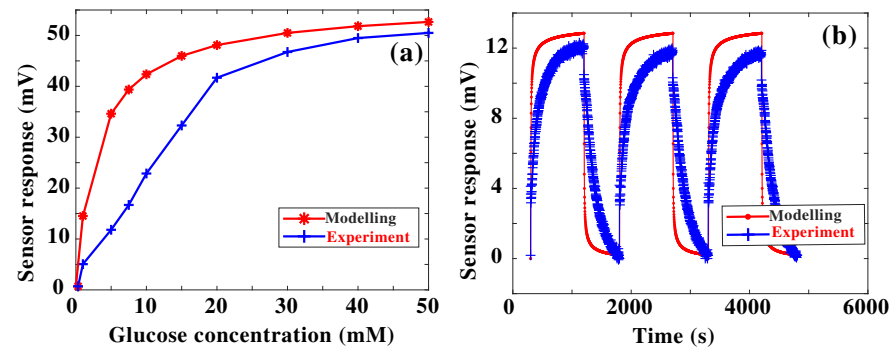

Fig. 9. Comparison between modeling and experimental data: (a) sensor response versus glucose concentration for $\Delta V_{p}=0.27 \mathrm{~V}$ and $\boldsymbol{T}_{p o l}=5 \mathrm{~min}$.(b) Sensor response over time with successive constant polarization $\Delta V_{p}=0.27 \mathrm{~V}, \boldsymbol{T}_{p o l}=15 \mathrm{~min}$ and $C_{0}=10^{-3} \mathrm{~mol} / \mathrm{L}$.

range.Whereas the polarization voltage increases the sensor response, the sensitivity and the dynamic range. Our numerical model compared to experimental data shows a similar shape, giving a significant step on predicting glucose biosensor using ElecFET. However, the model needs to be improved by taking into account the buffer properties of the electrolyte solution. Nevertheless, it enables to better understand the detection principle of biosensor based on ElecFET device.

\section{REFERENCES}

[1] R.-A.-D. De Faria, H. Iden, L.G.D. Heneine, T. Matencio, Y. Messaddeq, "Non-Enzymatic Impedimetric Sensor Based on 3-Aminophenylboronic Acid Functionalized Screen-Printed Carbon Electrode for Highly Sensitive Glucose Detection," Sensors, vol. 19, p.1686, Apr. 2019, doi: $10.3390 / \mathrm{s} 19071686$

[2] N. H. Cho, J. E. Shaw, S. Karuranga, Y. Huang, J. D. F. Da Rocha, A.-W. Ohlrogge, B. Malanda, "IDF Diabetes Atlas: Global estimates of diabetes prevalence for 2017 and projections for 2045," Diabetes Res.Clin. Pract., vol.138, pp. 271-281, Apr. 2018, doi: 10.1016/j.diabres.2018.02.023.

[3] W. V. Gonzales, A. T. Mobashsher, A. Abbosh, "The Progress of Glucose Monitoring-A Review of Invasive to Minimally and NonInvasive Techniques, Devices and Sensors," Sensors, vol. 19, p. 800, Feb. 2019, doi: 10.3390/s19040800.

[4] J. Wang, "Electrochemical glucose biosensors," Chem. Rev., vol.108, pp. 814-825, Dec. 2007, doi: 10.1021/cr068123a.

[5] R. Feeney, P. Kounaves, "Microfabricated microelectrodes arrays: Developments, advances and applications in environmental analysis," Electroanal, vol. 12, pp. 677-684, Jun. 2000, doi: 10.1002/15214109(200005)12:9;677::AID-ELAN677;3.0.CO;2-4.

[6] S. Laschi, M. Mascini, "Planar electrochemical sensors for biomedical applications," Med. Eng. Phys., Vol.28, pp. 934-943, Dec. 2006, doi: 10.1016/j.medengphy.2006.05.006.

[7] R. De Marco, G. Clarke, B. Pejcic, "Ion-Selective Electrode Potentiometry in Environmental Analysis," Electroanal, vol.19, pp. 1987-2001, Oct. 2007, doi: 10.1002/elan.200703916.

[8] P. Bergveld, "Thirty years of ISFETOLOGY: What happened in the past 30 years and what may happen in the next 30 years," Sens. Actuator BChem, vol. 88, pp. 1-20, Jan. 2003, doi: 10.1016/S0925-4005(02)003015.

[9] B.-K. Sohn, C.-S. Kim, "A new pH-ISFET based dissolved oxygen sensor by employing electrolysis of oxygen," Sens. Actuator B, vol.34, pp. 435-440, Aug. 1996, doi: 10.1016/S0925-4005(97)80017-2.

[10] A.-K. Diallo, L. Djeghlaf, L. Mazenq, J. Launay, W. Sant, P. TempleBoyer, "Development of pH-based ElecFET biosensors for lactate ion detection," Biosens. Bioelectron., vol. 40, pp. 291-296, Feb. 2013, doi: 10.1016/j.bios.2012.07.063.

[11] H.-I. Seo, C.-S. Kim, B.-K. Sohn, T. Yeow, M.-T. Son, M. Haskard, "ISFET glucose sensor based on a new principle using the electrolysis of hydrogen peroxide," Sens. Actuator B-Chem, vol. 40, pp.1-5, May. 1997, doi: 10.1016/S0925-4005(97)80191-8.

[12] B.-K. Sohn, B.-W. Cho, C.-S. Kim, D.-H. Kwon, "ISFET glucose and sucrose sensors by using platinum electrode and photo cross-linkable polymers," Sens. Actuator B-Chem, vol.41, pp. 7-11, Jun. 1997, doi: $10.1016 / \mathrm{S} 0925-4005(97) 80271-7$.
[13] C. Heitzinger, R. Kennell, G. Klimeck, N. Mauser, M. McLennan, C. Ringhofer, "Modeling and simulation of field-effect biosensors (BioFETs) and their deployment on the nanoHUB,"'in J. Phys.: Conf. Ser.,Alberta,Canada,2008, pp. 012004.

[14] L.-J. Mele, P. Palestri, L. Selmi, "A model of the interface charge and chemical noise due to surface reactions in Ion Sensitive FETs," in Proc. of SISPAD,Udine,Italy,2019,pp.343-346.

[15] P. Temple-Boyer,J. Le Gal, M.-L. Pourciel-Gouzy,W. Sant, A. Martinez, "Modelling of EnFETs for the creatinine detection," Sens. Actuator BChem, vol. 118, pp. 47-52, Oct. 2006, doi: 10.1016/j.snb.2006.04.011.

[16] P. Temple-Boyer, A. Benyahia, W. Sant, M.-L. Pourciel-Gouzy, J. Launay, A. Martinez, "Modelling of urea-EnFETs for haemodialysis applications," Sens. Actuator B-Chem, vol. 131, pp. 525-532, May. 2008 , doi: 10.1016/j.snb.2007.12.037.

[17] J. Ch. Dutta, S. Roy, "Modeling Neuron for Simulation of Transmitter Gated Ion Channels of Postsynaptic Membrane at Synaptic Cleft," Am. J. Biomed. Sci., vol. 3, pp. 176-182, Mar. 2011, doi: 10.5099/aj110300176.

[18] A. H. Pourasl, M. T. Ahmadi, M. Rahmani, H. Ch. Chin, Ch. S. Lim, R. Ismail, M. L. P. Tan, "Analytical modeling of glucose biosensors based on carbon nanotubes," Nanoscale. Res. Lett.,vol. 9, Jan 2014, doi: 10.1186/1556-276X-9-33

[19] Y. Hanazato, S. Shiono, M. Maeda, "Response Characteristics of the glucose-sensitive field-effect transistor Computer simulation of the effect of gluconolactonase coimmobilization in a glucose oxidase membrane," Anal Chim Acta, vol. 231, pp. 213-220, Apr. 1990, doi: 10.1016/S00032670(00)86419-3.

[20] S. D. Caras, D. Petelenz, J. Janata, "pH-Based Enzyme Potentiometric Sensors. Part2.Glucose-Sensitive Field Effect Transistor," Anal Chem, vol. 57, pp. 1920-1923, Aug. 1985, doi: 10.1021/ac00286a028.

[21] A. K. Diallo, L. Djeghlaf, L. Mazenq, J. Launay, W. Sant, P. TempleBoyer, "Modelling of impulsional $\mathrm{pH}$ variations using ChemFET-based microdevices: application to hydrogen peroxide detection," Sensors, vol. 14, pp. 3267-3283, Feb. 2014, 10.3390/s140203267.

[22] N. Aoun, F. Echouchene, A. K. Diallo, J. Launay, P. Temple-Boyer, H. Belmabrouk, "Finite-Element Simulations of the Ph-ElecFET Microsensors," IEEE Sens. J., vol. 16, 6519-6526, Sep. 2016, doi: 10.1109/JSEN.2016.2585506.

[23] A. P. Soldatkin, A. V. El'skaya, A. A. Shul'ga, L. I. Nctchiporouk, A. M. NyamsiHendji, N. Jaffrezic-Renault, C. Martelet, "Glucosesensitive field-effect transistor with additional Nafion membrane," Anal. Chim. Acta, vol. 283, pp. 695-701, Nov. 1993, doi: 10.1016/00032670(93)85284-Q.

[24] A. A. Shul'ga, M. Koudelka-Hep, N. F. de Rooij, L. I. Netchiporouk, "Glucose-sensitive enzyme field effect transistor using potassium ferricyanide as an oxidizing substrate,"Anal. Chem., vol. 66, pp. 205-210, Jan. 1994, doi: 10.1021/ac00074a005.

[25] V. Volotovsky, A. P. Soldatkin, A. A. Shul'gac, V. K. Rossokhaty,V. L. Strikha, A. V. El'skaya, "Glucose-sensitive ion-sensitive field-effect transistor-based biosensor with additional positively charged membrane. Dynamic range extension and reduction of buffer concentration influence on the sensor response," Anal. Chim. Acta., vol. 322, pp.77-81, Mar. 1996, doi: 10.1016/0003-2670(95)00592-7.

[26] L. T. Yin, J. C. Chou,W. Y. Chung, T. P. Sun, K. P. Hsiung, S. K. Hsiung, "Glucose ENFET doped with MnO2 powder," Sens. Actuator B-Chem, vol. 76, pp.187-192, Jun. 2001, doi: 10.1016/S0925-4005(01)00629-3.

[27] K. Saeedfar, L. Y. Heng, T. L. Ling, M. Rezayi, "Potentiometric Urea Biosensor Based on an Immobilised Fullerene-Urease Bio-Conjugate," Sensors, vol. 13, pp. 16851-16866, Dec. 2013, doi: 10.3390/s131216851.

[28] M. Alqasaimeh, L. Y. Heng, M. Ahmad, A. S. Raj, T. L. Ling, "A Large Response Range Reflectometric Urea Biosensor Made from SilicaGel Nanoparticles," Sensors, vol. 14, pp. 13186-13209, Jul. 2014, doi: $10.3390 / \mathrm{s} 140713186$. 